\title{
A Revista Matéria é aceita no SciELO
}

A primeira revista científica virtual da área de materiais tem a sua qualidade reconhecida ao tornar-se uma revista indexada na coleção SciELO.

"A SciELO - Scientific Electronic Library Online é uma biblioteca virtual para a publicação eletrônica cooperativa de periódicos científicos na Internet. Ela foi especialmente desenvolvida para responder às necessidades da comunicação científica nos países em desenvolvimento e particularmente na América Latina e Caribe. A SciELO contém ainda procedimentos integrados para medir o uso e o impacto dos periódicos científicos. O modelo SciELO contém três componentes, descritos a seguir.

O primeiro componente é a Metodologia SciELO, que permite a publicação eletrônica de edições completas de periódicos científicos, a organização de bases de dados bibliográficas e de textos completos, a recuperação de textos por seu conteúdo, a preservação de arquivos eletrônicos e a produção de indicadores estatísticos de uso e impacto da literatura científica. A Metodologia também inclui critérios de avaliação de revistas, baseado nos padrões internacionais de comunicação científica.

O segundo componente do Modelo SciELO é a aplicação da Metodologia SciELO na operação de websites de coleções de revistas eletrônicas. O Modelo SciELO favorece a operação de sites nacionais e também de sites temáticos. A aplicação pioneira é o site SciELO Brasil (http://www.scielo.br - com 159 revistas disponíveis). Também estão em operação aplicações no Chile (http://www.scielo.cl - disponibilizando 56 revistas), em Cuba (http://www.scielo.sld.cu - disponibilizando 19 revistas) e na Venezuela (http://www.scielo.org.ve - disponibilizando 18 revistas).

O terceiro componente do Modelo é o desenvolvimento de alianças entre os atores nacionais e internacionais da comunicação científica - autores, editores, instituições científico-tecnológicas, agências de financiamento, universidades, bibliotecas, centros de informação científica e tecnológica etc, com o objetivo de disseminar, aperfeiçoar e atualizar o Modelo SciELO."

A aceitação da Revista Matéria na coleção SciELO e a sua inserção neste sistema, o que demanda um importante trabalho de editoria que se fará nos meses que se seguem, representa uma indexação de aceitação internacional. Isso valoriza ainda mais os trabalhos publicados pela revista e amplia consideravelmente a sua abrangência. Vale ressaltar que no ano de 2006 o número de acessos à revista já é o dobro daquele experimentado em 2005. 
Nossos parabéns aos autores, que vêm publicando seus artigos na Revista Matéria, e ao Corpo Editorial e de Revisores da revista, que vem executando o trabalho criterioso de revisão e de avaliação de artigos. Estas ações conjuntas garantiram a qualidade, ora reconhecida, que serve de garantia de valor para os artigos publicados.

Não hesite em submeter os melhores resultados da sua pesquisa para publicação na Revista Matéria para garantir uma divulgação científica eficiente e de reconhecida qualidade.

Cordialmente,

Paulo Emílio V. de Miranda

Editor-Chefe da Revista Matéria

pmiranda@labh2.coppe.ufrj.br

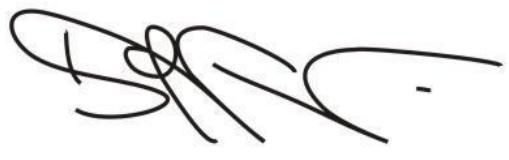

